\title{
e-interview
}

\section{Bill Fulford}

Bill Fulford is Professor of Philosophy and Mental Health at the University of Warwick; Honorary Consultant Psychiatrist and Fellow of St Cross College, University of Oxford; Professor and Co-Director of the Institute for Philosophy, Diversity and Mental Health at the University of Central Lancashire; and Special Adviser for Values Based Practice in the Department of Health.

What has been the greatest impact of your profession on you personally? Working as a psychiatrist has provided a unique opportunity to bring together my interest in philosophy with day-to-day clinical practice and scientific research. Psychiatry presents particular conceptual challenges (e.g. the many problems raised by the concept of mental disorder) together with uniquely difficult ethical problems and problems of conflicting values (e.g. in relation to compulsory treatment). These problems have been made even more acute by advances in the neurosciences. So this has been a particularly exciting period to work in this cross-disciplinary area.

\section{What job gave you the most useful} training experience?

I was fortunate to get onto the Maudsley Training rotation in the 1970s. This provided me with an opportunity to work with several first-class psychiatrists including Sir Denis Hill, Peter Scott, Alwyn Lishman and John Crammer. In addition, I had the further tremendous experience of doing a $\mathrm{PhD}$ in psychology with GlenWilson in Hans Eysenck's department. The training programme at the Maudsley also gave me the flexibility to continue my work in philosophy and it was this that, with the support of Michael Gelder in Oxford, led to my doing my DPhil in philosophy with Baroness Warnock

\section{How has the political environment} influenced your work?

Much of my work over the last few years has been as Special Advisor for Values Based Practice in the Department of Health. With support from a number of key policymakers as well as service users, clinicians and others, this has made it possible to take forward a series of 'philosophy into practice' initiatives in several areas of policy, training and research. These initiatives have also involved a number of exciting international developments

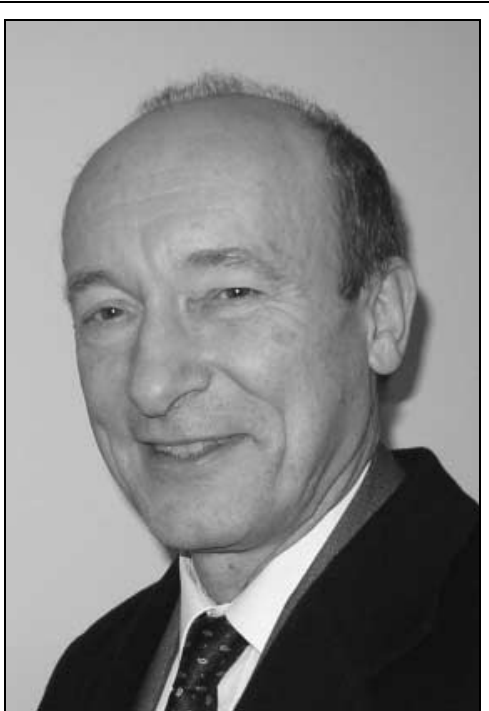

whole persons that it has to encompass mind and brain and of course the social environment as well. It is from this that the particular challenges of psychiatry clinical, scientific and philosophical - all arise.

What single area of psychiatric practice is most in need of development?

Well, values-based practice, but then would say that! The point here is that although values-based approaches have been adopted in many areas of training and service development in mental health and social care, there is an urgent need to extend the approach into other areas of medicine. Psychiatry could lead the way here but at least in the UK, values-based approaches are currently being developed most actively in other areas of primary care such as general practice.

\section{What is the most promising} opportunity facing the profession?

Psychiatry has been at the forefront of developing genuine partnership in decisionmaking between, on the one hand, patients and carers as service users, and on the other, clinicians, researchers and managers as service providers. This partnership works most effectively when it is founded equally on evidence-based and values-based approaches. Hence, the most promising opportunity facing us at the present time is to build further on this partnership between service users and service providers in the context of unprecedented advances in the sciences underpinning psychiatry.

\section{What is the most important advice} you could offer to a new trainee? In my experience, new trainees are ill prepared for the stigmatisation that they are likely to experience when they go into psychiatry. In my own case, the most important advice that I was given, and that helped me to deal with this stigmatisation, was to recognise and keep coming back to the fact that psychiatry is perhaps the last of the medical disciplines to remain firmly person-centred in its approach. It is in the nature of psychiatry that we can only do our job properly if we relate to the person as a whole rather than limiting ourselves to a particular organ or bodily part

Do you think psychiatry is brainless or mindless?

Neither! It is precisely because psychiatry by its very nature has to deal with people as
What single area of psychiatric research should be given priority? The philosophy of psychiatry - but again I would say that, wouldn't I! The serious point behind this answer is, again, that psychiatry has a real opportunity to take the lead here, in this case in developing a model of medical science that incorporates, on an equal basis, rigorous conceptual alongside rigorous empirical methods.

In the 20th century the stigmatisation of psychiatry included treating the subject as though it were somehow a failed or underdeveloped part of medical science. Properly understood, the opposite is the case - psychiatry is simply the most difficult of the medical sciences. The brain is after all the most difficult organ to study. But remember that the 'proper object of study' in psychiatry is neither brain nor mind but the whole person.

Recognising and embracing psychiatry's potential role in leading the way with the development of a model of medical science that is properly focused on the whole person would, I believe, take us a long way towards reversing 20th century stereotypes and the stigmatisation that went with them. This depends, critically, on an effective methodological pairing of conceptual and empirical research methods.

Dominic Fannon 